\title{
Research on Poverty Reduction Effect of Inclusive Finance in China Ethnic Areas*
}

\author{
Jianqiong Peng \\ Southwest Minzu University \\ Chengdu, China 610041 \\ Yangtze Normal University \\ Chongqing, China 408100
}

\begin{abstract}
This paper uses panel data to empirically analyze the relationship between inclusive finance and poverty alleviation in ethnic areas in 2010-2017. It is found that: first: the overall development of inclusive finance in the region is at a relatively low level with IFI at around 0.37 . Second: The development of inclusive finance in ethnic areas can promote poverty alleviation to a certain extent. Third: Economic growth, employment status, and urbanization have good poverty reduction effects. Finally, relevant policy recommendations are proposed for the development of inclusive finance to alleviate poverty in ethnic areas.
\end{abstract}

Keywords-inclusive finance; poverty reduction; ethnic areas

\section{INTRODUCTION}

In recent years, remarkable achievements have been made in poverty alleviation in ethnic areas in China. However, due to poor infrastructure and poor foundations, ethnic areas are the key and difficult areas for poverty alleviation. There are many reasons for poverty in these areas. Among them, financing is one of the main causes. As the allocation center of social resources, financial development has played an important role in promoting poverty alleviation for a long time. Financial instruments are increasingly being used as an important means of reducing poverty. The extent to which the development of inclusive finance in ethnic areas plays a role in poverty alleviation is worthy of further study.

\section{LITERATURE REVIEW}

Scholars generally believe that the development of inclusive finance can play a certain role in poverty alleviation, and that micro finance can increase residents' income and improve their resistance to risks. Bakhtiari (2006) believes that micro-finance institutions such as micro-finance can directly improve the income-generating capacity of the poor, and can also improve the efficiency of resource allocation and promote economic growth to indirectly promote poverty reduction. Claessens S, Feyen (2016) believes that increasing the availability of financial services, through the provision of inclusive financial services such as micro-finance and micro-finance, enables the poor to directly

*Fund: The paper is supported by Southwest Minzu University Graduate Innovative Research Project (Project No.: CX2016BS03). participate in more financial activities, increase their expected income and reduce poverty. Du Xiaoshan (2006) pointed out that the inclusive financial system will open up financial markets for the vast majority of people in developing countries, including those in the poorer and more remote areas that were difficult to reach in the past, providing credit, insurance and funds for the poor: settlement and other services. Zhang Lijun and Zhan Yong (2006) believe that micro-finance can increase the income of households and achieve the effect of alleviating poverty. Luo Sidan (2016) pointed out that China's regional inclusive financial development is unbalanced, and the eastern region is superior to the central and western regions; there are widespread financing problems in various regions of the country. In the short run, the improvement of inclusive financial level can significantly reduce the level of poverty reduction. In the long run, the development of inclusive finance will curb the slowdown of poverty. From the perspective of poverty reduction, there is an optimal level of inclusive financial development.

However, few studies took the ethnic areas as example, and this paper selects relevant data of eight provinces and regions, constructs inclusive financial indicators, and combines the poverty situation in ethnic areas to analyze the relationship between inclusive financial development and poverty alleviation in ethnic areas. It is aimed to provide effective advice for improving the development of inclusive finance in ethnic areas and promoting poverty alleviation.

\section{MEASUREMENT INDICATORS AND EMPIRICAL ANALYSIS}

This paper uses index from three dimensions: financial service penetration, product contact dimension and utility. The indicator system must reflect different aspects of inclusive financial development, and can scientifically measure the information contained in the basic connotation of inclusive finance.

The first is the penetration of financial services. From the perspective of financial supply, it mainly examines the degree of penetration of financial services provided by a region to clients, and indicates whether poor groups have access to and opportunities for financial services. The more outlets and practitioners in a financial institution in a region, 
the stronger their financial penetration will be. The penetration of financial services can be divided into the penetration of geographic dimensions and the penetration of population dimensions. In terms of geographical penetration, this paper selects indicators for the number (D1) of banking financial institutions (per 10,000 square kilometers) and the number (D2) of employees in banking financial institutions (per 10,000 square kilometers). The higher the indicator value, the more geographical penetration of financial services will be. In terms of population dimension, the selected indicators are the same: the number (D3) of banking financial institutions (per 10,000 people), the number (D4) of employees in banking financial institutions (per 10,000 people), which indicates to what extent a regional financial supply can financial services are provided by the poor, and the higher the indicator value, the stronger the population penetration of financial services.

The second is the contact dimension of financial products. Considering the use of financial resources from the perspective of financial demand, this paper combines the characteristics of major financial assets of residents in ethnic areas, and mainly selects two indicators: per capita deposit balance (yuan) (D5) and per capita loan balance (yuan) (D6).

The third is the utility of financial services. It mainly examines how much financial services are used (how many people get and how many are obtained). In order to reflect the utility of financial services for residents in ethnic areas, this paper selects four indicators: savings rate (\%) (D7), loan rate (\%) (D8), insurance depth (\%) (D9), and insurance density (yuan/person) (D10). They can reflect the use of financial services, and the extent of contribution to the economic development of ethnic areas. The higher the indicator value, the higher the utility of financial services in ethnic areas.

In this paper, the coefficient of variation is used to determine the weight of each indicator.

$$
W_{i}=\frac{V_{i}}{\sum_{1}^{n} V_{i}}
$$

$V_{\mathrm{i}}$ is the coefficient of variation of each indicator. A greater weight $W_{\mathrm{i}}$ means a greater contribution in the system. Since the units of different indicators are different, it is necessary to normalize the indicators to obtain specific measurement values of each indicator. Using the linear threshold method, after normalization, the measure values of each indicator are $\mathrm{d}_{\mathrm{i}}=\mathrm{w}_{\mathrm{i}} \times\left(\mathrm{X}_{\mathrm{i}}-\mathrm{m}_{\mathrm{i}}\right) /\left(\mathrm{M}_{\mathrm{i}}-\mathrm{m}_{\mathrm{i}}\right)$. Where $\mathrm{X}_{\mathrm{i}}$ is the actual value of the $i$-th indicator, $M_{i}$ is the maximum value of the $i$-th indicator, $m_{i}$ is the minimum value of the $i$ th indicator, and $\mathrm{w}_{\mathrm{i}}$ is the weight of the $\mathrm{i}$-th indicator. A greater $d_{i}$ indicates a higher inclusive financial level.

The IFI (Inclusive Finance Index) can be expressed as:

$$
I F I=1-\frac{\sqrt{\left(W_{1}-D_{1}\right)^{2}+\left(W_{2}-D_{2}\right)^{2}+\ldots+(W i-D i)^{2}}}{\sqrt{W_{1}^{2}+W_{2}^{2}+\ldots+W_{n}^{2}}}
$$

The value of the IF financial index IFI is $[0,1]$, and the closer its value is to 1 , the higher the level of development of inclusive finance.

According to the above calculation method, the "China Regional Financial Operation Report" and the relevant statistical yearbook data of each district are used to calculate the inclusive financial development index of the minority areas: (See "Table I")

TABLE I. IFI

\begin{tabular}{|l|l|l|l|l|l|l|l|l|}
\hline Areas & Ningxia & Yunnan & Guizhou & $\begin{array}{c}\text { Inner } \\
\text { Mongolia }\end{array}$ & Guangxi & Xinjiang & Qinghai & Tibet \\
\hline 2004 & 0.768 & 0.51 & 0.47 & 0.283 & 0.522 & 0.247 & 0.172 & 0.071 \\
\hline 2005 & 0.765 & 0.454 & 0.528 & 0.273 & 0.556 & 0.226 & 0.167 & 0.062 \\
\hline 2006 & 0.785 & 0.408 & 0.542 & 0.274 & 0.553 & 0.226 & 0.166 & 0.062 \\
\hline 2007 & 0.793 & 0.499 & 0.52 & 0.274 & 0.524 & 0.219 & 0.167 & 0.056 \\
\hline 2008 & 0.752 & 0.438 & 0.323 & 0.443 & 0.362 & 0.414 & 0.242 & 0.061 \\
\hline 2009 & 0.826 & 0.467 & 0.363 & 0.457 & 0.381 & 0.422 & 0.274 & 0.052 \\
\hline 2010 & 0.848 & 0.468 & 0.393 & 0.465 & 0.383 & 0.424 & 0.308 & 0.054 \\
\hline 2011 & 0.81 & 0.411 & 0.336 & 0.446 & 0.344 & 0.417 & 0.286 & 0.066 \\
\hline 2012 & 0.807 & 0.38 & 0.301 & 0.448 & 0.309 & 0.42 & 0.282 & 0.08 \\
\hline 2013 & 0.772 & 0.378 & 0.341 & 0.427 & 0.308 & 0.405 & 0.283 & 0.092 \\
\hline 2014 & 0.748 & 0.391 & 0.362 & 0.412 & 0.296 & 0.404 & 0.296 & 0.108 \\
\hline 2015 & 0.773 & 0.369 & 0.356 & 0.419 & 0.281 & 0.396 & 0.3 & 0.112 \\
\hline 2016 & 0.73 & 0.37 & 0.347 & 0.415 & 0.258 & 0.377 & 0.285 & 0.12 \\
\hline 2017 & 0.592 & 0.654 & 0.788 & 0.415 & 0.231 & 0.418 & 0.434 & 0.3 \\
\hline Mean & 0.769 & 0.437 & 0.423 & 0.398 & 0.368 & 0.367 & 0.268 & 0.094 \\
\hline No. & 1 & 2 & 3 & 4 & 5 & 6 & 7 & 8 \\
\hline
\end{tabular}


It can be seen from the relevant data (see "Table I") that the IFI value in Ningxia is about 0.7 , which is a relatively high level. Yunnan and Guizhou are basically maintained at around 0.4, which is a general level; Inner Mongolia, Guangxi, and Xinjiang are basically around 0.3, Qinghai is around 0.2 , and Tibet is the lowest, only 0.093 . For the entire ethnic minority region, the development level of inclusive finance is at a relatively low level, and IFI is basically maintained at around 0.37. Although it reached its maximum in 2017 , it was only 0.479 .

\section{EMPIRICAL ANALYSIS}

\section{A. Model Design and Variable Selection}

In order to analyze the impact of inclusive finance on poverty alleviation in ethnic areas, this paper takes the incidence rate of poverty $\mathrm{H}$ as the dependent variable and the inclusive financial index IFI as the independent variable. The control variables are as follows: The level of development, industrial structure, urbanization level, and education level are included in the model. The employment status is recorded as employment, which is expressed as the proportion of the total employed population in the province to the total population of the province. This paper uses the actual per capita GDP of each province and region, lnpgdp, as an indicator to measure the economic development level of a region. The industrial structure is expressed by the total agricultural output value/GDP. The level of urbanization is expressed by the urban population/total population. The educational level of Lnedu is expressed in logarithm with the number of people receiving secondary education per 100,000 population. The poverty indicator comes from the incidence of rural poverty in the past years published in the Rural Poverty Test Report; other data are from the China Financial Yearbook, the China Statistical Yearbook, and the statistical yearbooks of various years. The quantity units involved in the price are converted. It is expressed in the constant price of 2000. This paper selects the panel data of the eight provinces and regions in 2010-2017, and uses the Stata15.0 software to build the following model:

$$
H_{i t}=\alpha_{0}+\alpha_{1} I F I_{i t}+\beta_{i} X_{i t}+\varepsilon_{\mathrm{it}}
$$

Where is the number of regions, IFI is the independent variable, Hit is the dependent variable, $i$ is the region, $t$ is the time, $\mathrm{H}$ is the poverty, $\alpha 0$ is the intercept term, $\alpha 1$ is the coefficient. (See "Table II")

TABLE II. VARIABLE DESCRIPTIVE STATISTICS

\begin{tabular}{|c|c|c|c|c|c|}
\hline Variable & Obs. & Mean & S E. & Min. & Max. \\
\hline H & 64 & 0.1797 & 0.1105 & 0.0270 & 0.4920 \\
\hline IFI & 64 & 0.3945 & 0.1869 & 0.0536 & 0.8480 \\
\hline lnpgdp & 64 & 9.0016 & 0.2536 & 8.4140 & 9.4135 \\
\hline employment & 64 & 0.4885 & 0.1578 & 0.0740 & 0.6708 \\
\hline structure & 64 & 0.1281 & 0.0974 & 0.0454 & 0.7926 \\
\hline urban & 64 & 0.4479 & 0.0989 & 0.2267 & 0.6202 \\
\hline lnedu & 64 & 8.8793 & 0.1584 & 8.5033 & 9.2238 \\
\hline
\end{tabular}

\section{B. Analysis of Empirical Results}

Since the involved time is short, and the relevant indicators take the logarithm, this paper considers it to be a stationary sequence and does not test the data stability. By performing the $\mathrm{F}$ test and the Hausman test on the model, the null hypothesis is rejected, and the fixed effect model should be used. The regression results are as follows:

Since the poverty index uses the incidence of rural poverty in ethnic areas, this indicator is positive, that's, the higher the incidence of poverty, the higher the poverty level; on the contrary, the lower the poverty level; from the regression results, the IFI coefficient is negative. 0.040, and is significant at the $5 \%$ level, indicating that the povertystricken financial development in the ethnic areas has a significant poverty alleviation effect. For every $1 \%$ increase in IFI, the incidence of poverty will fall by $0.040 \%$. (See "Table III")

TABLE III. REGRESSION RESULT

\begin{tabular}{|c|c|c|c|c|}
\hline Variable & Coefficient & $\begin{array}{c}\text { Standard } \\
\text { error }\end{array}$ & $\mathbf{t}$ & $\mathbf{p}$ \\
\hline IFI & -0.040 & 0.066 & -0.60 & 0.013 \\
\hline lnpgdp & -0.409 & 0.093 & -4.40 & 0.000 \\
\hline employment & -0.648 & 0.233 & -2.50 & 0.008 \\
\hline structure & -0.090 & 0.059 & -1.52 & 0.136 \\
\hline urban & -1.933 & 0.215 & -8.97 & 0.000 \\
\hline lnedu & 0.242 & 0.109 & 2.22 & 0.031 \\
\hline$\alpha$ & 2.908 & 1.045 & 2.75 & 0.008 \\
\hline
\end{tabular}

Among the control variables, for every $1 \%$ increase in employment level, the incidence of poverty in ethnic areas decreased by $0.648 \%$; for every $1 \%$ increase in urbanization rate, the incidence of poverty will decrease by $1.933 \%$; the increase in employment level will increase the income of poor groups. At the same time, along with the advancement of urbanization, more poor residents in cities and towns have increased their means of income, and overall income levels have improved, thus improving poverty. The educational expenditure on behalf of the education level accounts for a positive correlation between the regional fiscal expenditure ratio and the incidence of poverty in rural areas. One possible explanation is that although the number of people receiving minority education in ethnic areas has increased, the number of educated population in rural areas tends to be large. Urban work has the problem of the loss of human capital; the industrial structure and the incidence of poverty in ethnic areas are not significant. It shows that the total agricultural output value has no obvious effect on poverty alleviation. In addition to increasing the total agricultural output value, it should pay attention to the quality and efficiency of agricultural industry.

\section{CONCLUSIONS AND POLICY RECOMMENDATIONS}

\section{A. Conclusions}

This paper measures the development of inclusive finance in ethnic areas, and combines the rural poverty situation in ethnic areas to empirically analyze the impact of 
inclusive finance on poverty alleviation in ethnic areas, and draws the following conclusions:

During 2004-2017, the overall level of inclusive financial development in ethnic areas was at a relatively low level, and IFI remained at around 0.37 . The development of inclusive finance in Ningxia is higher, while Tibet is the lowest.

The development of inclusive finance in ethnic areas has a certain role in promoting poverty alleviation.

Economic growth, employment status, and urbanization have good poverty reduction effects, but the anti-poverty effect of education level is positively correlated. The relationship between industrial structure and poverty reduction is not significant, indicating that rural areas in ethnic areas should pay attention to local technology. The employment of the labor force is followed by the improvement of the quality and efficiency of the agricultural industry.

\section{B. Countermeasures}

Firstly, it is suggested to improve the inclusive financial service system, continue to give full play to the advantages of traditional financial institutions in the areas of capital and network accumulated in ethnic areas, transform these comparative advantages into service advantages, and continue to do basic financial services such as deposits and loans that can meet the basic financial needs of the poor, and further enhance the quality of basic financial services.

Secondly, it is necessary to innovate financial products and service means, intensify financial innovation, innovate financial products, reduce the cost of financial transactions, and extend financial services to low-income and underdeveloped areas in ethnic areas to maximize the economic benefits of poverty alleviation resources in a more precise manner.

Thirdly, it is necessary to steadily improve the level of urbanization in ethnic areas, not only pay attention to quantity, but also focus on quality; raise the level of human capital stock in ethnic areas, actively introduce local employment incentives for talents, and improve employment institutions in ethnic areas. At the same time, it's a must to pay attention to the optimization of agricultural industrial structure in rural areas in ethnic areas, focusing on the improvement of quality and efficiency.

\section{REFERENCES}

[1] Bakhtiari S. Micro-finance and Poverty Reduction: Some International Evidence. International Business \& Economics Research Journal, 2006, 5(12): 65-71.

[2] Claessens S, Feyen E. Finance and Hunger: Empirical Evidence of the Agricultural Productivity Channel [J]. Social Science Electronic Publishing, 2016:1-48(48)

[3] Sarma M. Index of Financial Inclusion [C]. Indian Council for Research on International Economic Relations, New Delhi, India, 2015.

[4] Du Xiaoshan. The Development of Micro-finance and the Framework of Inclusive Financial System [J]. Beijing: China Rural Economy, 2006 (8): 70-74
[5] Zhang Lijun, Zhan Yong. Financial Development and Poverty Reduction - Based on the Analysis of Chinese Small-scale Credits [J]. Contemporary Economic Science [J], 2006(11): 36-42.

[6] Luo Dan, Chen Xiao, Yao Yuexin. Research on the Poverty Reduction Effect of China's Inclusive Financial Development [J] Journal of Contemporary Economic Research, 2016(12): 84-93.

[7] Wang Xiuhua, Key. The Measurement of Rural Financial Inclusion Level and Income Distribution Effect in China [J]. China Soft Science, 2014(08): 150-161.

[8] Wei Lili, Li Peipei. Research on Anti-poverty Effect of Inclusive Finance - Based on Panel Data Analysis in Western Regions [J]. Industrial Technology Economy, 2017, 36(10): 38-44.

[9] Lu Yuyang. Study on the Anti-poverty Effect of Rural Financia Development in Ethnic Areas [J]. Rural Economy, 2016(01): 95-102. 